\title{
Predicted response of the calving glacier Svartisheibreen, Norway, and outbursts from it, to future changes in climate and lake level
}

\author{
Michael Kennett, ${ }^{1 *}$ Tron Laumann, ${ }^{2}$ Bjarne KJøllmoen ${ }^{1}$ \\ ${ }^{1}$ Norwegian Water Resources and Energy Administration, Box 5091 Majorstua, N-0301 Oslo, Norway \\ ${ }^{2}$ Nordbyveien 179, N-2013 Skjetten, Norway
}

\begin{abstract}
The Svartisheibreen glacier in northern Norway has been investigated since 1988 in connection with a proposed hydropower scheme. The scheme includes regulation of the lake into which the glacier calves. A one-dimensional flow model has been used to estimate the response of the glacier to changes in mass balance and lake level. The model predicts that a net balance, excluding calving, of $0 \mathrm{~m} \mathrm{a}^{-1}$ will cause the glacier to retreat approximately $400 \mathrm{~m}$ over 50 years if lake level is maintained at $774 \mathrm{~m}$ a.s.l., but that the glacier front will not move significantly if lake level is lowered to $720 \mathrm{~m}$ a.s.l. In 1989 and 1991, lake outbursts occurred beneath the glacier. The 1991 outburst was monitored, and culminated in a peak discharge of only $3.5 \mathrm{~m}^{3} \mathrm{~s}^{-1}$, much less than for other reported outbursts. This outburst can be explained in a model in which the outburst tunnel passes over a subglacial threshold approximately $70 \mathrm{~m}$ behind the 1991 calving front. The model shows that outbursts will probably increase dramatically in size if the front retreats beyond this threshold.
\end{abstract}

\section{INTRODUGTION}

Svartisheibreen is a small calving valley glacier of $5.5 \mathrm{~km}^{2}$ close to Svartisen in northern Norway (Fig. 1). Aerial photographs show that the lake Heiavatnet, into which the glacier calves, first appeared between 1945 and 1968. Lake size has increased significantly from $0.04 \mathrm{~km}^{2}$ in 1968 to $0.30 \mathrm{~km}^{2}$ currently. The glacier has been a focus of scientific investigation since 1988 in connection with a proposed hydropower development. The lake normally drains over a rock threshold R (Fig. 1) where a water intake (I1) is planned; however, the plans include the option of artificially lowering lake level via a lake intake. In May 1989, lake level was observed to have dropped since the previous winter. This can only be due to an outburst beneath the glacier tongue and out through a gully G (Fig. 1) at the southern margin of the glacier and about $500 \mathrm{~m}$ from the lake; this is believed to be the first outburst since before the 18th-century Little Ice Age. Lake level was subsequently logged and a second outburst was recorded in 1991. This event was undramatic compared with other documented outbursts (e.g. Clague and Mathews, 1973), taking $5 \mathrm{~d}$ or so to reach a peak discharge of only $3.5 \mathrm{~m}^{3} \mathrm{~s}^{-1}$. The 1991 outburst is not detectable in the hydrograph at the Berget discharge station $18 \mathrm{~km}$ downstream from G. Similarly, the 1989 event cannot be seen in the Berget hydrograph, suggesting that this was also a lowdischarge event. To date these are the only two outbursts that have occurred from Heiavatnet.

\footnotetext{
* Present address: National Remote Sensing Centre, Southwood Crescent, Farnborough GU14 0NL, England
}

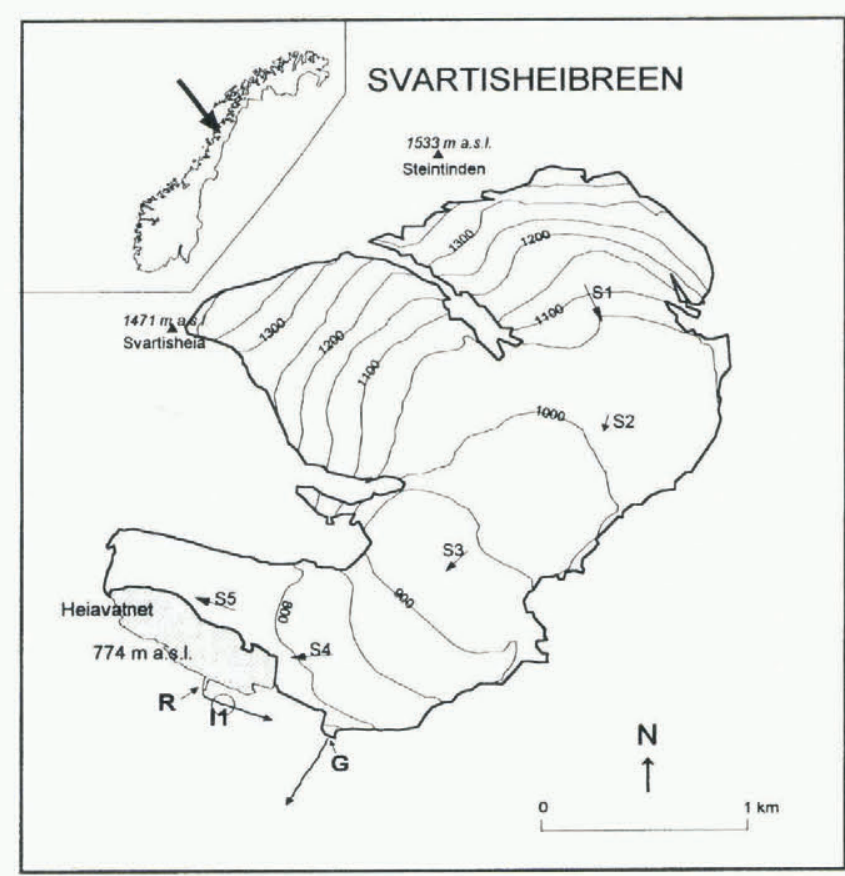

Fig. 1. Svartisheibreen in northern. Norway, showing positions of rock threshold $R$, gully $G$ and proposed intake II. Arrows indicate ice-velocity vectors at stakes $S 1\left(44 \mathrm{ma}^{-1}\right), S 2$ $\left(16 m a^{-1}\right), S 3\left(33 m a^{-1}\right), S 4\left(45 m a^{-1}\right)$ and S5 $\left(44 m a^{-1}\right)$. Contours are of surface elevation in $m$ a.s.l.

The future development of Svartisheibreen and Heiavatnet is of great importance to the power scheme, which would operate for at least 40 years. Outburst floods from Heiavatnet, which is currently the largest ice-dammed lake in Norway, are a potential hazard, and divert water away 


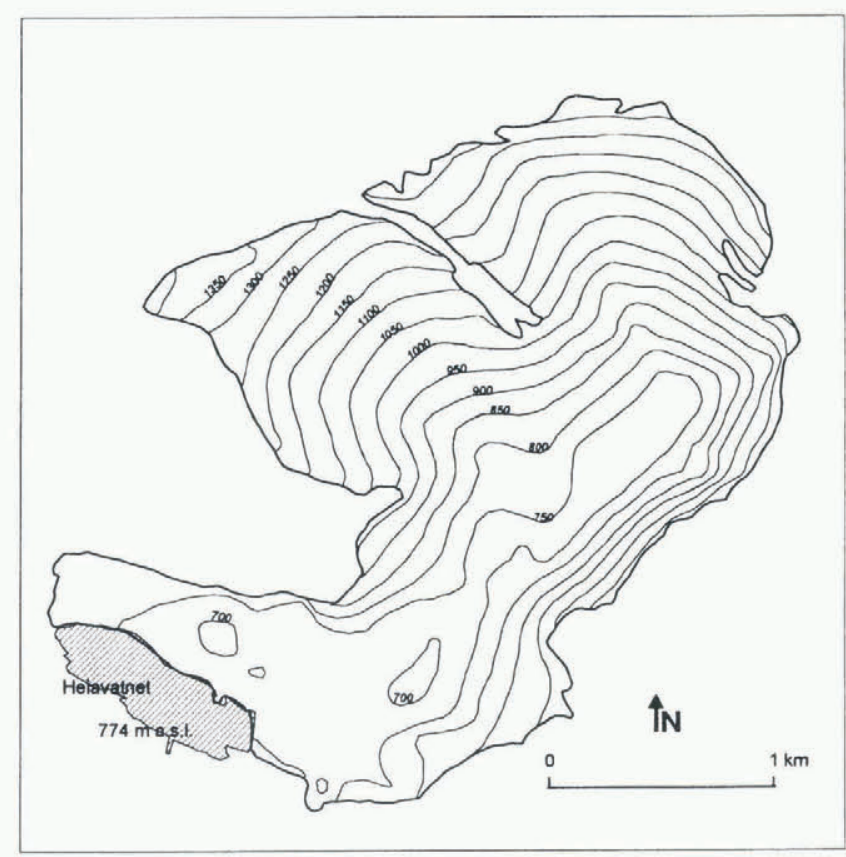

Fig. 2. Bed topography of Svartisheibreen. Contours are in ma.s.l.

from intake I1. Models of glacier motion and lake outbursts have therefore been used to estimate possible changes to the Svartisheibreen, Heiavatnet and lake outbursts over the coming decades.

\section{FUTURE GHANGES TO GLAGIER GEOMETRY}

Measurements of ice thickness, mass balance and ice velocity were used to construct a numerical model of the present glacier, in order to predict the response of the glacier to future change in climate and lake level. The bed topography (Fig. 2), obtained in 1990 using radar (Kjøllmoen and Kennett, 1995), shows a deep trough below normal lake level stretching over $2 \mathrm{~km}$ up-glacier from the lake. Mass balance was measured for the seven mass balance years 1988-94, for which the average yearly specific winter, summer and net balances (excluding calving) were $+3.11,-2.56$ and $+0.55 \mathrm{~m}$ (water equivalent), respectively. However, measurements of glacier surface elevation and front position show that glacier geometry has remained reasonably stable during the measurement programme. We estimate therefore that average calving is equivalent to approximately $-0.55 \mathrm{ma}^{-1}$ mass balance, i.e. $3.0 \times 10^{6} \mathrm{~m}^{3} \mathrm{a}^{-1}$ (water) volume. Ice surface velocity was measured from 1990 to 1994 using a series of stakes, and velocity vectors are shown in Figure 1.

A time-dependent one-dimensional flow model based on that of Bindschadler (1982) has been used. The model calculates glacier surface profile vs time from continuity and a simplified flow law. The three-dimensional nature of a glacier is approximated by parameters which take account of friction from valley sides. The model used here includes a calving component (Laumann, 1987) in which the calving rate is related to water depth at the calving front. Funk and Röthlisberger (1989) deduced empirically a linear relationship between calving speed $u_{c}$ (in $\mathrm{m} \mathrm{a}^{-1}$ ) and water depth $H_{\mathrm{w}}(\mathrm{m})$ averaged across the calving front:

$$
u_{\mathrm{c}}=1.9 H_{\mathrm{w}}+12 .
$$

However, the development of Heiavatnet since 1968 is consistent with a calving speed given by

$$
u_{\mathrm{c}}=0.6 H_{\mathrm{w}} .
$$

This much-reduced calving activity is not unreasonable since Heiavatnet is ice-covered for all but a few weeks of the year and contains a large number of icebergs, so water circulation is minimal and water temperature is maintained at $0^{\circ} \mathrm{C}$.

The model was tuned for Svartisheibreen using data on glacier geometry, mass balance (using also data from Engabreen, $13 \mathrm{~km}$ further north, prior to 1988) and ice velocities, and was then run for combinations of three mass-balance and two lake-level scenarios: net balance excluding calving, $b_{\mathrm{n}}{ }^{\prime}$, equal to $+1,0$ and $-1 \mathrm{~m} \mathrm{a}^{-1}$; and lake level equal to 774 and $720 \mathrm{~m}$ a.s.l. A separate mass-balance model (Laumann and Reeh, 1993) shows that an increase in net balance of $1 \mathrm{~m} \mathrm{a}^{-1}$ on Svartisheibreen would result from a change in air temperature throughout the year of approximately $-1.2, \mathrm{C}$, or in precipitation of approximately $+30 \%$. The results in Figure 3 show that $b_{\mathrm{n}}{ }^{\prime} \approx 0.5 \mathrm{~m} \mathrm{a}^{-1}$ is required to maintain the current front position with a lake level of $774 \mathrm{~m}$ a.s.l., consistent with measurements. A balance of $b_{\mathrm{n}}{ }^{\prime}=0 \mathrm{ma}^{-1}$ would cause a steady retreat due to calving loss. This retreat is likely to be more pronounced over the first 5 years or so, as thinning would cause the lower part of the tongue to float and break off.
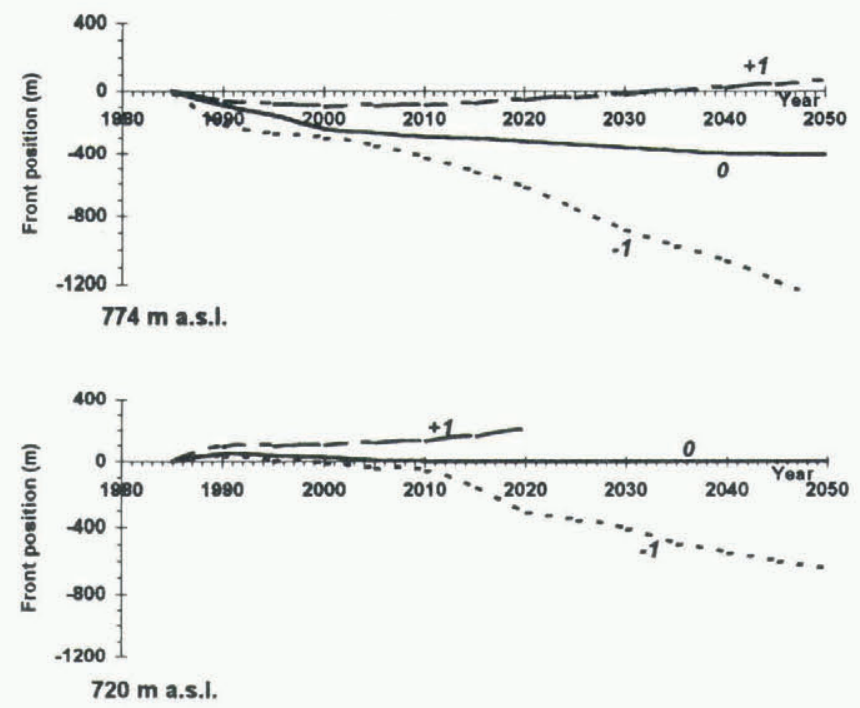

Fig. 3. Predicted front position for Svartisheibreen relative to 1985 position for lake level $=774 \mathrm{~m}$ a.s.l. (above) and $720 m$ a.s.l. (below), and for $b_{\mathrm{n}}{ }^{\prime}=+1 m a^{-1}$ (dashed lines), 0 (solid lines) and $-1 m a^{-1}$ (dotted lines).

\section{PREDICTION OF LAKE OUTBURSTS}

Glacier outbursts can represent a serious hazard. Hydrographs typically show a discharge which increases rapidly up to several hundred or thousand $\mathrm{m}^{3} \mathrm{~s}^{-1}$, followed by a sharp cut-off (e.g. Clarke, 1982; Björnsson, 1992). The waterlevel record and derived discharge for the 1991 Heiavatnet event are shown in Figure 4. Discharge rose slowly over approximately $5 \mathrm{~d}$, culminating in a peak of only $3.5 \mathrm{~m}^{3} \mathrm{~s}^{-1}$. The cut-off, although more rapid than the rise, is still not sharp. Lake level did not return to $774 \mathrm{~m}$ a.s.l. until May 1992. In order to explain this small outburst and predict 

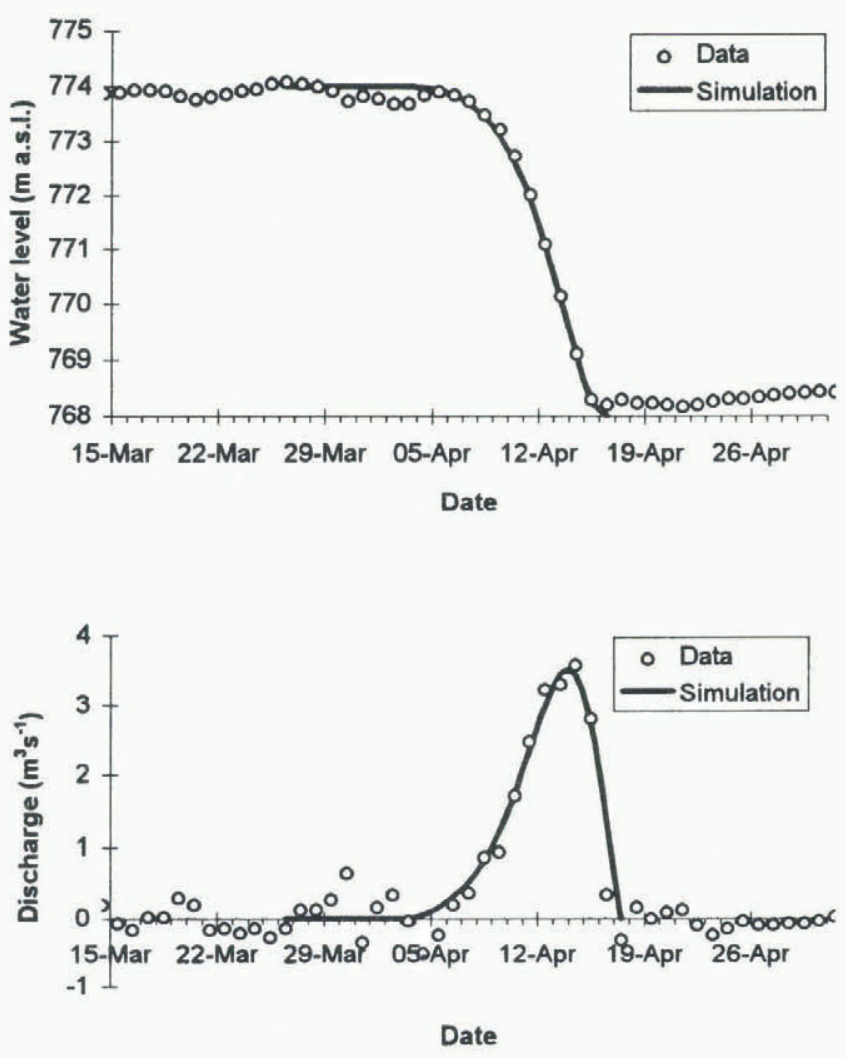

Fig. 4. Water level in Heiavatnet (above) and derived net discharge (below) from the lake during the 1991 outburst event (circles), and results of simulation using model M2 with $n=0.105 \mathrm{~m}^{-\frac{1}{3}} \mathrm{~s}, S=70 \mathrm{~m}, Q_{\text {in }}=0.3 \mathrm{~m}^{3} \mathrm{~s}^{-1}, H_{l}=774 \mathrm{~m}$, $H_{0}=768 \mathrm{~m}, \mathrm{~A}=300000 \mathrm{~m}^{2}, T_{\mathrm{w}}=0^{\circ} \mathrm{C}$ ( solid line). The discharge data values are calculated from $Q=$ $-A_{\mathrm{L}} \mathrm{d} H / \mathrm{d} t$, thus increases in lake level produce the apparent negative discharges.

the magnitude of future outbursts as front position changes, a simple outburst-simulation model was developed. Model M1 (Fig. 5a) consists of a cylindrical tunnel with a single straight section. Discharge $Q_{\text {c }}$ through such a tunnel with cross-sectional area $A$ is given by

$$
Q_{\mathrm{c}}=\frac{A^{\frac{4}{3}}\left(-\mathrm{d} Z_{\mathrm{h}} / \mathrm{d} s\right)}{(4 \pi)^{\frac{1}{3}} n}
$$

(Clarke, 1982), where

$$
Z_{\mathrm{h}}=Z+\frac{P_{\mathrm{w}}}{\rho_{\mathrm{w}} g}
$$

is hydraulic head elevation, $s$ is distance along the tunnel, $n$ is Manning roughness coefficient, $P_{\mathrm{w}}$ is water pressure, $\rho_{\mathrm{w}}$ is water density, and $g$ is acceleration due to gravity. We assume that all potential and thermal energy in the water is used to melt tunnel walls such that the tunnel is enlarged at a rate given by

$$
\frac{\mathrm{d} A}{\mathrm{~d} t}=\frac{-Q_{\mathrm{c}} \rho_{\mathrm{w}}\left(\left(g \mathrm{~d} Z_{\mathrm{h}} / \mathrm{d} s\right)+\left(C \mathrm{~d} T_{\mathrm{w}} / \mathrm{d} s\right)\right)}{L \rho_{\mathrm{i}}}
$$

where $\rho_{\mathrm{i}}$ is ice density, $T_{\mathrm{w}}$ is water temperature, $C$ is the specific heat capacity of water and $L$ is the latent heat of melting of ice. We assume here that closure rates are negligible compared to melt rates. For Svartisheibreen, effective pressure (ice overburden pressure less water pressure) in the outburst tunnel is probably no more than 5 bar, so closure rates (relative change in tunnel diameter) are less than $3 \% \mathrm{~d}^{-1}$.
This compares with tunnel growth rates of up to $50 \% \mathrm{~d}^{-1}$ during simulations of outbursts from Heiavatnet. Finally lake level $H$ is related to discharge by

$$
\frac{\mathrm{d} H}{\mathrm{~d} t}=\frac{Q_{\text {in }}-Q_{\mathrm{c}}-Q_{\mathrm{out}}}{A_{\mathrm{L}}},
$$

where $Q_{\text {in }}$ is the rate of inflow to the lake from its catchment, $Q_{\text {out }}$ is the outflow rate by means other than through the outburst tunnel (i.e. discharge over the rock threshold $\mathrm{R}$ in the case of Svartisheibreen), and $A_{\mathrm{L}}$ is lake area. The time evolution of an outburst is solved using these equations in a simple computer program in which melt rate is assumed to be constant along the length of the tunnel. Discharge data from other outbursts suggest that $n$ is $0.08-0.12 \mathrm{~m}^{-\frac{1}{3}} \mathrm{~s}$ (Nye, 1976; Clarke, 1982; Björnsson, 1992). Model Ml gives a good fit to observed water-level records for outbursts from Hazard Lake using the parameters used in the model of Clarke (1982), despite the relative simplicity of $\mathrm{Ml}$. However, in a simulation of the 1991 Heiavatnet event using $n=0.105 \mathrm{~m}^{-\frac{1}{3}} \mathrm{~s}$ and $T_{\mathrm{w}}=0^{\circ} \mathrm{C}$, model $\mathrm{Ml}$ predicts a peak discharge of $26 \mathrm{~m}^{3} \mathrm{~s}^{-1}$, much larger than the observed peak of $3.5 \mathrm{~m}^{3} \mathrm{~s}^{-1}$. An unrealistically large roughness of $\mathrm{n}=0.9 \mathrm{~m}^{-\frac{1}{3}} \mathrm{~s}$ is required to reproduce the observed discharge. In addition, this simulation produces a discharge curve with a positive second derivative with respect to time until discharge stops abruptly, unlike the observed curve (Fig. 4).

To explain the very low discharge from Heiavatnet, an alternative model, M2 (Fig. 5b), with a subglacial threshold $\mathrm{T}$, has been developed. Here we assume that the threshold has an elevation equal to the water-level $\mathrm{H}_{2}$ at the end of the outburst. We expect that water pressure at $\mathrm{T}$ will be equal to atmospheric pressure if the slope in elevation from
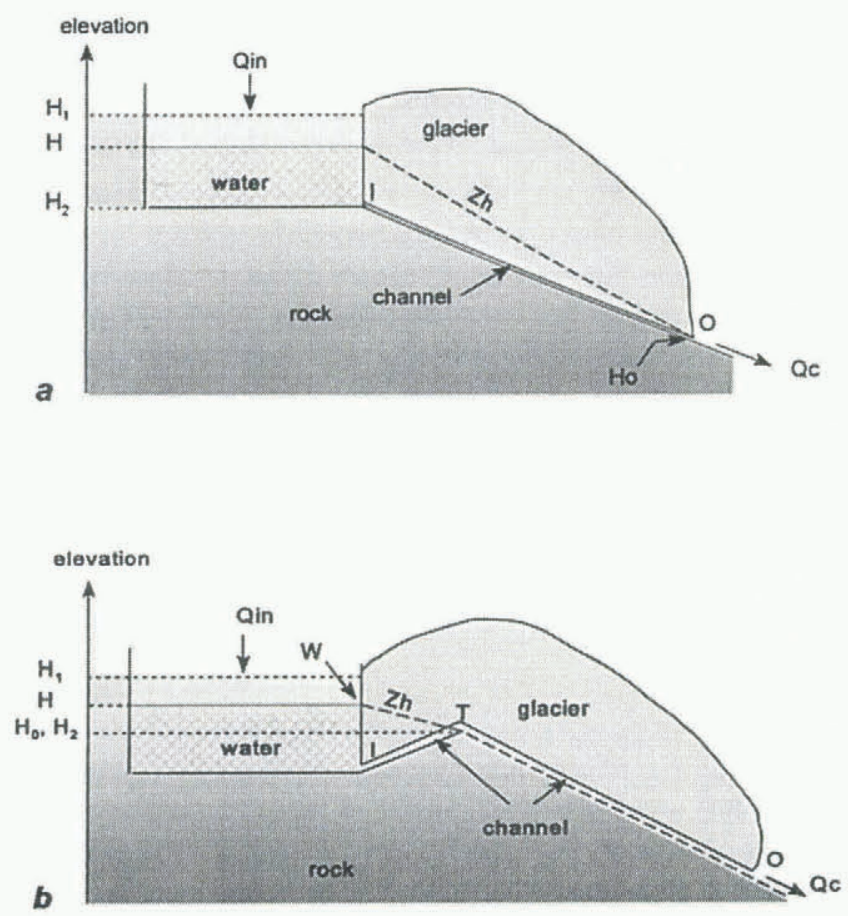

Fig. 5. Schematic diagrams of conceptualized outburst tunnels (a) with a single straight section, and (b) with a subglacial threshold $T$. $H$, lake level at time $t ; \mathrm{H}_{1}$ and $\mathrm{H}_{2}$ lake level at start and end of outburst; $H_{b}$ elevation of (effective) outlet; $Z_{\mathrm{h}}$, hydraulic head elevation along tunnel; $Q_{\text {in }}$, input into lake; $Q_{\mathrm{c}}$, discharge through outburst tunnel; I and $O$, tunnel start and end; $W$, waterline on calving front. 
$\mathrm{T}$ to $\mathrm{W}$ is less than that from $\mathrm{O}$ to $\mathrm{T}$ (Fig. $5 \mathrm{~b}$ ). This is because the energy available for melting tunnel walls between $T$ and $\mathrm{O}$ will then be more than sufficient to maintain an open conduit (Hooke, 1984). The effective outlet is thus at T, such that it is the section from I to $\mathrm{T}$ that controls the discharge, with $S$ equal to the distance I-T, and $H_{0}=H_{2}$. Very good fits to the observed hydrograph can be obtained from model M2 for $60 \mathrm{~m}<S<80 \mathrm{~m}$ with $T_{\mathrm{w}}=0^{\circ} \mathrm{C}, Q_{\text {in }}<1 \mathrm{~m}^{3} \mathrm{~s}^{-1}$ and $0.08<n<0.12$, with the best fit for $Q_{\text {in }}=0.3 \mathrm{~m}^{3} \mathrm{~s}^{-1}$. Such an input into Heiavatnet is quite reasonable in April. Simulated discharge and lake-level curves are shown in Figure 4. We conclude that the 1991 outburst tunnel passed over a subglacial rock threshold Tapproximately $70 \mathrm{~m}$ from the calving front.

The exact path of the tunnel is unknown, but such a tunnel can only exist close to the southern edge of the glacier between Heiavatnet and G (Fig. 2). The bed topography is not mapped accurately enough to localize the supposed threshold T, but the map indicates that $\mathrm{T}$ must lie closer to

Table 1. Results from model M1 for Heiavatnet without a subglacial threshold for various values of lowest lake level $\mathrm{H}_{2} . \mathrm{V}$, total water volume through outburst tunnel; $Q_{\max }$, peak discharge through tunnel; $t_{\max }$, time to peak discharge after discharge has passed $1 \mathrm{~m}^{3} \mathrm{~s}^{-1}$. Other model parameters as in model M2 simulation in Figure 4 except $H_{0}=700 \mathrm{~m}$, $S=500 m$

\begin{tabular}{cccc}
\hline $\begin{array}{c}H_{2} \\
\text { ma.s.l. }\end{array}$ & $\begin{array}{c}V \\
\times 10^{6} \mathrm{~m}^{3}\end{array}$ & $\begin{array}{c}Q_{\max } \\
\mathrm{m}^{3} \mathrm{a}^{-1}\end{array}$ & $\begin{array}{c}t_{\max } \\
\mathrm{h}\end{array}$ \\
\hline 768 & 1.8 & 26 & 71 \\
760 & 4.2 & 66 & 86 \\
750 & 7.2 & 115 & 96 \\
740 & 10.2 & 146 & 102 \\
\hline
\end{tabular}

the lake than to $\mathrm{G}$, which is consistent with the results of the modelling. The outburst release mechanism is not known, but meteorological data from Glomfjord, approximately $20 \mathrm{~km}$ north of Svatisheibreen, show that an unusually warm period began on 3 April 1991 and lasted for $10 \mathrm{~d}$. One possibility therefore is that this caused the opening of a subglacial channel which was then captured by the lake around 7 April. The ice surface slopes steeply towards the margin between gully $\mathrm{G}$ and the lake such that we expect a concentration of normal subglacial drainage close to the margin here. The timing of the 1989 outburst is unknown, but a similar warm period occurred in April of that year.

The possibility and magnitude of future outbursts depends on changes to glacier geometry. A thinning of the ice dam around $\mathrm{T}$ will increase the likelihood of an outburst since the ice dam will come closer to flotation. However, major changes will occur if the front retreats, as is predicted if the climate returns to pre-1989 conditions with $b_{\mathrm{n}}{ }^{\prime} \approx$ $0 \mathrm{~m} \mathrm{a}^{-1}$ (Fig. 3). We suppose that the outburst will find ways around the threshold $\mathrm{T}$ as the glacier retreats, such that the situation will become that of other outbursts (model Ml, Fig. 5a). Table 1 gives results from model Ml for Heiavatnet without a subglacial threshold, and shows that peak discharge may increase dramatically to over $100 \mathrm{~m}^{3} \mathrm{~s}^{-1}$. Here we have made the approximation that lake area $A_{\mathrm{L}}$ is constant as water level drops, but have not taken account of the fact that $A_{\mathrm{L}}$ will increase and hydraulic head gradient will steepen as the glacier retreats. The values in the table are therefore highly approximate. The results show nevertheless that future outbursts may become a significant hazard.

\section{CONGLUSIONS}

The appearance of Heiavatnet after 1945 has had a large effect on Svartisheibreen, particularly since 1968 with increased calving due to greater water depth at the calving front as the glacier has retreated. This retreat has halted since 1989 due to a consistent positive net balance over the upper surface of the glacier, which has been enough to counterbalance the large amount of calving at the front. However, measurements of ice thickness suggest the glacier front is still in an unstable position, with further retreat causing deeper water at the front and thus increased calving. The glacier response so far is consistent with the results of a one-dimensional time-dependent flow model. This model shows that the glacier will retreat steadily well into the next century if net balance (excluding calving) is zero and lake level remains at $774 \mathrm{~m}$ a.s.l., with an initial more rapid retreat over the first 5 years or so. Front position can be controlled to a certain extent by regulating Heiavatnet.

Lake outbursts have occurred in 1989 and 1991 but in none of the other years since the measurement programme began in 1988. These are probably the only two outbursts beneath Svartisheibreen since before the 18th-century Little Ice Age, so we are fortunate to have data from one of them. The 1991 outburst reached a maximum discharge of only $3.5 \mathrm{~m}^{3} \mathrm{~s}^{-1}$ as lake level dropped by $6 \mathrm{~m}$. The uncharacteristically low peak discharge has been explained using a simple model of the development of the outburst channel, which includes a subglacial threshold with an elevation equal to lake level at the end of the outburst. This threshold is believed to be approximately $70 \mathrm{~m}$ behind the 1991 calving front. Using the model it has been shown that outbursts may increase dramatically in size if the glacier retreats to this threshold and beyond. If Svartisheibreen retreats, outbursts will become more likely, possibly occurring every year. Further retreat will lead to larger outbursts which will probably occur before lake level has reached $774 \mathrm{~m}$ a.s.l., such that an intake at Il (Fig. 1) would be permanently dry. Thus, Svartisheibreen would seem to be in a transition phase between no outbursts and yearly outbursts.

The outbursts that have occurred at Svartisheibreen would almost certainly not have been noticed had it not been for the measurement programme on the glacier. This raises the possibility of similar unnoticed small outbursts beneath other glaciers.

\section{ACKNOWLEDGEMENTS}

The authors are grateful to the Norwegian Power Board (Statkraft) for commissioning the measurements described here, and to other members of the Glaciology Section of the Norwegian Water Resources and Energy Administration for assistance with data collection and analysis. 


\section{REFERENGES}

Bindschadler, R. 1982. A numerical model of temperate glacier flow applied to the quiescent phase of a surge-type glacier. F. Glaciol., 28 (99), 239-265.

Björnsson, H. 1992. Jökulhlaups in Iceland: prediction, characteristics and simulation. Ann. Glaciol., 16, 95-106.

Clague, J.J. and W. H. Mathews. 1973. The magnitude of jökulhlaups. F. Glaciol., 12(66), 501-504.

Clarke, G. K. C. 1982. Glacier outburst floods from "Hazard Lake", Yukon Territory, and the problem of flood magnitude prediction. F. Glaciol., $28(98), 3-21$.

Funk, M. and H. Röthlisberger. 1989. Forecasting the effects of a planned reservoir which will partially flood the tongue of Unteraargletscher in
Switzerland. Ann. Glaciol., 13, 76-81.

Hooke, R. LeB. 1984. On the role of mechanical energy in maintaining subglacial water conduits at atmospheric pressure. F. Glaciol., 30(105), 180187.

Kjøllmoen, B. and M. I. Kennett. 1995. Breundersökelser på Svartisheibreen 1988-94. Oslo, Norges Vassdrags-og Energiverk. (NVE Rapport 171995.)

Laumann, T. 1987. En dynamisk modell for isbreers bevegelse. Oslo, Norges Vassdrags-og Energiverk. Hydrologisk Avdeling. (NVE Publikasjon V-8.)

Laumann, T. and N. Reeh. 1993. Sensitivity to climate change of the mass balance of glaciers in southern Norway. f. Glaciol., 39(133), 656-665.

Nye, J. F. 1976. Water flow in glaciers: jökulhlaups, tunnels and veins. $\mathcal{f}$. Glaciol., 17(76), 181-207. 